\title{
What actually works to enhance graduate employability? The relative value of curricular, co-curricular, and extra-curricular learning and paid work.
}

\begin{abstract}
The focus on short-term graduate employment metrics has catalysed the employability agenda as a strategic directive in universities. A raft of embedded, co-curricular and extra-curricular activities have emerged for developing employability. Their relative value lacks empirical exploration. This study explored graduates' selfreported participation in, and their perspectives on the value of, a range of embedded, extra-curricular and cocurricular learning activities, as well as paid work, for employability. Survey data were gathered $(N=510)$ from Business and Creative Industries graduates from three Australian universities about the perceived value of activities for: skill development, gaining relevant experience, networking, and creating employment opportunities. The activities were considered more useful for gaining experience and skills than for broadening networks and improving career outcomes. Embedded and extra-curricular internships, as well as extra-curricular activities, were believed to be important for enhancing employability. Internships organised as an extra-curricular activity rated better than those delivered as work-integrated learning. Implications for stakeholders responsible for curricular and co-curricular design are discussed.
\end{abstract}

\section{Keywords}

Experiential learning; work-integrated learning; skills development; employability; extra-curricular activities. 
As the higher education (HE) sector has become increasingly competitive, there has been a growing focus on graduate employment outcomes as a way of gauging institutional quality and students' return on investing in degree studies (Blackmore et al. 2016). This has highlighted employability as a strategic directive (Smith et al. 2018), with league tables encompassing employment outcomes, and government funding for HE being made contingent upon graduate outcome performance, such as with the Teaching Excellence Framework in the UK and Performance Based Funding for universities in Australia (for example, Australian Government 2019). Aligning to the human capital perspective, where developing skills and knowledge will heighten an individual's economic value and therefore enhance their career prospects (Becker 1964), national HE policies link superior professional capabilities with enhanced employment outcomes. Rightly or wrongly, universities are now tasked with developing these, acquiring responsibility for fostering student employability. There is, however, not always a positive relationship between student capabilities and graduate employment (Burke et al. 2017). This can be mediated by individual characteristics, such as social and cultural capital (Clarke 2017) and job seeking behaviours and flexibility (Guilbert et al. 2016), and external factors, including recruitment bias, location, and labour market demand (Guilbert et al. 2016; Horverak et al. 2013).

In this study, we consider employability to be a multi-dimensional, lifelong and life-wide phenomenon that is malleable and driven by the individual, yet encouraged and facilitated by HE. We acknowledge debate on the purpose of HE and concerns for vocationalisation arising from the discourse of employability (Smith et al. 2018). We also understand there are some influences beyond the control of educational input yet believe many determining factors of student employability have clear implications for HE learning and teaching practice and delivering pedagogy and opportunities that enhance employability is therefore vital. As the strategic importance of employability grows, so does the pressure on academics, learning designers and career specialists to facilitate effective interventions through embedded, co-curricular and extra-curricular pathways. Embedded employabilityrelated activities are those integrated into curricula as a formal component of students' learning and may form part of their assessment. Co-curricular activities are facilitated by the university yet sit outside the students' formal course of study, often designed and delivered by central services, such as careers provision. Extra-curricular activities are organised externally, undertaken by students with no formal involvement from their university, other than perhaps advertising the opportunity. 
Numerous embedded, co-curricular and extra-curricular activities (ECAs) for developing employability continue to emerge (Smith et al. 2018). Despite the wealth of literature on employability, there appears to be little empirical exploration of their relative value, including how this varies among diverse student cohorts. This study examined graduate perspectives on the value of these different activities, as well as paid work, in developing key employability indicators, namely skill development, gaining relevant experience, broadening of networks, and the creation of employment opportunities. The research objectives were to: (i) examine how self-reported participation in a range of learning activities and paid work varies by individual characteristics; (ii) explore the perceived relative value of a range of learning activities for enhancing employability; and iii) examine the role of certain activity design characteristics and individual variables on their perceived value for enhancing employability. Data were gathered from Business and Creative Industries graduates of three Australian universities, ranging from one to five years post-course completion. The paper first considers ways of enhancing student employability, followed by methodology, presentation of results and implications for stakeholders responsible for curricular and co-curricular design.

\section{Background}

\section{Gauging impact on student employability}

Despite the wealth of studies showcasing and evaluating activities and assessments to augment employability, very few appear to contrast and compare their relative impact. One exception is Kinash and colleagues' (2016) useful review of strategies designed to enhance employability from the perspective of educators, employers, students and graduates. These included capstone initiatives, mentoring programs, international exchanges, professional association and other networking events, social media networks, volunteering and work experience. There is also commentary from Cranmer (2006) who questioned the value of campus-based programs for developing professional skills, although acknowledging the value of industry involvement in design and delivery. The overall lack of empirical assessment of the relative value-add of employability-focused interventions is surprising given the strategic importance of employability and the context of institutional resource constraints.

Comparing different activities requires the identification of key indicators of employability. Adopting an instrumental approach, one could gauge the extent to which the learning activities create employment opportunities. This is often achieved through national surveys which use narrow, short-term measures of graduate employment (Jackson and Bridgstock 2018), more indicative of transition-to-work than labour market 
achievements (Wilton 2012). Misalignment in the relationship between employability and employment outcomes means investing in a degree does not always 'pay off' in employment terms (Burke et al. 2017; Wilton 2012) and individuals and their attending institutions may not always see the immediate returns on investing significantly in quality curricula designed to enhance student employability. Burke and colleagues argue employability is 'represented in simplistic terms as an objective labour market outcome rather than a complex problem featuring a number of different actors' (p. 115) and certainly gauging the effectiveness of learning activities should be complemented by other measures.

Given the favouring of the human capital lens, another commonly explored indicator of employability is disciplinebased and professional skill development (the latter also referred to as transferable, generic, non-technical, or 'soft' skills). Reservations have been expressed (Holmes 2013) on HE's ability to successfully develop students' skills in areas such as communication, teamwork, critical thinking and problem-solving, given the differences between campus and professional settings. The strategic push for enhancing employability has, however, seen rapid growth in embedded, within-subject material, core modules and external programs dedicated to skill development, as well as co-curricular awards using portfolios and other sophisticated software for students to evidence and articulate their development and demonstration of these skills (Smith et al. 2018). Numerous reports list changes in future required capabilities and resulting skill gaps due to digitalisation and automation (for example, AIG 2018; Bakhshi et al. 2018). Despite the theoretical framing of employability broadening to other dimensions, professional skill outcomes remain a key indicator of student employability. Forms of measurement often include self-report skill audits and portfolios at different time points during degree studies (for example, Oliver 2013).

A further indicator of employability is the ability to interact meaningfully with professionals and establish and effectively leverage networks for the purposes of realising career goals (Bridgstock and Tippett 2019). The importance of students broadening their networks and refining their networking capabilities is increasingly recognised as critical to their employability. Well-developed professional social networks afford direct access to career opportunities and resources (Batistic and Tymon 2017). Professional networking can also enhance students' cultural capital, developing their understanding of values, conduct and behaviours appropriate to professional life (Fugate and Kinicki 2001), and can aid career identity development by enabling students to experience, visualise and discuss career pathways (Bridgstock 2019). Bridgstock asserts that gauging networking capabilities and the extent of networks is relatively underexplored and lacking in empirical examination. 
Finally, there is strong evidence that students both desire and expect meaningful exposure to industry during their studies to enhance their preparedness for work and aid career prospects (Tymon 2013). They favour practical components that connect them with employers, exposing them to current practice and enabling them to visualise and apply their theoretical learning beyond the classroom setting (Jackson 2019). Tymon found that students are eager to gain relevant work experience, particularly international students who often select their country of education based on such opportunities (Cturtle and Decision Lab 2019). Employers also value applied learning activities, particularly internships (Hart Research Associates 2018), and work experience has become a highly regarded selection criterion among graduate employers (NACE 2018). Although evaluating student participation in activities that provide relevant experience may not be difficult, deciphering their relative benefit can pose challenges given the complexities associated with defining and gauging individual learning gain with respect to employability (Williams, Dodd, Steele, and Randall 2016), and the sector's tendency to focus on employment proxy measures.

\section{Activities to enhance student employability}

Work-Integrated Learning (WIL) is one pathway for enhancing HE student employability and has attracted increasing attention in Australia, catalysed by its National Strategy (Universities Australia et al. 2015). It refers to embedding learning activities and assessment that involves students in meaningful industry and/or community engagement, encompassing both workplace-based activities (placements, practicums and internships) and virtual or campus-based activities (client projects, industry panels, consultancies, start-up/incubators, virtual placements and mentoring programs). The latter are of particular interest given the difficulties in scaling up workplace-based WIL where student demand for work experience often outstrips available employer opportunities (Universities Australia 2019). WIL provides a key platform for employers and HE to collaborate on developing future talent to meet industry needs and close apparent skill gaps, such as teamwork, analytical reasoning and problem-solving (Bloomberg 2018).

Institutions have invested significantly in WIL, perceiving it to be positively associated with student employability. In turn, there has been increasing pressure to evaluate the 'employment value' of its various forms. Typically, there has been more attention to gauging the impact of workplace-based WIL (for example, McCarthy and Swayn 2019; Nghia and Duyen 2019) than emerging, virtual/campus-based models. With respect to the four employability 
indicators utilised in this study, there is a documented positive effect on both discipline-specific and professional skill outcomes (Deeley 2014; Jackson 2015), enabling students to visualise and practice applying skills in authentic settings. Second, it provides a unique opportunity for students to expand their networks and facilitates purposive interaction with role model professionals through assigned tasks and projects (Gibson 2004). Third, it provides a clear pathway for gaining relevant experience through the completion of authentic work and application of theoretical knowledge. The employment effect is, however, less clear. Several studies have detected a positive relationship (Jackson and Collings 2017; McCarthy and Swayn 2019; Silva et al. 2018) while earlier research reported no effect at all (Kinash et al. 2016; Wilton 2012).

There has been a growing focus on universities introducing co-curricular activities intended to enhance employability and create positional advantage for its graduating students (Berger and Wild 2017; Green et al. 2019). Examples include leadership and award programs, community engagement/outreach activities, competitions and hackathons, volunteering hubs, and student clubs/societies. In addition to WIL and co-curricular activities, paid work and a range of ECAs are widely considered to enhance our four indicators of student employability. First, ECAs enhance student self-confidence, self-awareness and student capability in a wide range of professional skills (Clark et al. 2015; Muldoon 2009). Clark and colleagues also found paid work particularly useful for enhancing communication and interpersonal skills while Coates (2015) reported its benefits for both discipline and professional skills-based learning. Both voluntary and paid work are considered to aid the development of networks among students (Coates 2015; Muldoon 2009).

The value of ECAs and paid work for gaining relevant experience is perhaps less clear, determined by the nature of the activity, with whom and in what context. Some, for example, have expressed caution on the value of paid work not relevant to degree studies (Gracia 2010; Kinash et al. 2016). There is some evidence that paid work and ECAs improve employment prospects (Jackson and Collings 2017; Purcell et al. 2012) although concerns have been raised for a negative effect on academic performance due to balancing time commitments (Hordósy, Clark and Vickers 2018; Thompson et al. 2013). Clark et al. (2015) reported that ECAs aided students' during recruitment and selection processes due to enhanced self-confidence and the signalling of certain capabilities to potential employers. Many have emphasised the importance of encouraging students to consider their ECAs, work and university-based learning activities in complement, requiring deep reflection on the meaning and value of achievements across their different activities (Clarke et al. 2015; Thompson et al. 2013). 


\section{Method}

\section{Participants}

The study's participants comprised 510 graduates of undergraduate programs (Business $=279$, Creative Industries=194, double degree=37) who graduated in 2013 (one to two years previously at the time of the survey, $N=242$ ) or in 2016 (four to five years previously at the time of the survey, $N=268$ ). Data were gathered on Creative Industries and Business graduates as it was anticipated these would capture contrasting curricular activities with respect to student employability, given their varying labour market contexts. Data were collected from graduates of three universities located in different States (university $1=101$, university $2=131$, university $3=278$ ). None are classified as research-intensive and each has a reputation for quality learning and teaching, particularly in relation to advancing student employability. A summary of participants' characteristics is presented in Table 1 . Consistent with HE student enrolments, approximately two-thirds of the graduates were female and a significant proportion were aged below 34 years. The high proportion of domestic graduates was expected, given the study was conducted up to five years post-course completion and many international students would no longer be in Australia. There were more Business graduate participants at both time periods.

\section{[Insert Table 1]}

\section{Procedures}

Eligible graduates - those that had graduated between 2013 and 2016 in Business or Creative Industries undergraduate programs - were invited to participate in an online survey by email, their contact details obtained via their respective university's alumni database. Two reminder emails were sent, an incentive was offered for survey completion and responses were gathered between October 2017 and March 2018.

\section{Measures}

In addition to background characteristics, the survey comprised questions on participation in university learning activities, ECAs and paid work. Respondents were presented with a list of learning activities, collapsed into the categories of for-credit, not-for-credit, co-curricular and paid work. They were asked to indicate their engagement in each, whether it was paid (or part-paid), its relevance to their degree, and the approximate number of hours and weeks they were engaged in the activity. They were also asked to rate the extent to which they interacted meaningfully with professionals from their field of interest during the learning activity. 


\section{Outcome variables}

Graduates were asked to rate how useful they believed each learning activity was for: a) learning new skills, b) gaining experience relevant to their desired career, c) broadening their networks, and d) creating employment opportunities. These four outcome variables were selected as established indicators of student employability, as discussed in the background review. All ratings were completed on a five-point Likert scale with a neutral point.

\section{Predictor variables}

First, students provided detail on their background characteristics (see Table 1). The second group of predictor variables were the characteristics of the activity, paid versus unpaid; extent of participation (duration); relevance of participation and the extent of meaningful interaction with professionals during the activity. These were selected given studies documenting differences for pay (McHugh 2017) and duration (Jackson and Wilton 2017), and the perceived importance of authenticity and relevance in quality WIL (Smith 2012).

\section{Analysis}

Survey data were aggregated and analysed using SPSS 24.0. To address the first research objective, variations in self-reported participation across different activities were examined by individual characteristics using nonparametric tests, Mann-Whitney U tests for comparing two independent groups, and Kruskal-Wallis tests for three or more. A Bonferroni correction was not applied, given the exploratory nature of the study. Variations by discipline were examined only for the major groups of Business and Creative Industries, given the small number who completed a degree in both $(N=37)$. To address the second research objective, the mean ratings, and associated standard deviations, were computed for the perceived usefulness of the learning activities and the extent to which they interacted with professionals. Further a composite mean was created for each type of learning activity to indicate their perceived value on average.

The third research objective was explored using multiple linear regression which was conducted to gauge the predictive value, if any, of activity design variables (duration, relevance to degree, pay and extent of interaction with professionals), institution and discipline on the composite employability indicator for for-credit internship/practicum/placements at the employer's place of work. This learning activity was selected due to sample size, ensuring it met Harrell's (2001) widely-used recommendation of a minimum 10 subjects-per-variable. 


\section{Results}

\section{Participation in learning activities}

Table 2 indicates that almost $60 \%$ of the sample reported they had participated in one or more of the for-credit learning activities as part of their studies. Most popular were internships/practicums/placements at the employers' place of work, followed by industry-based projects/consultancies; and internship/practicum/placement at their own university. Almost one-half of the sample participated in one or more of the not-for-credit learning activities with, again, the greatest proportion undertaking an industry-based internship. Far smaller proportions participated in mentoring, project/consultancies or an internship at their own university. Only $14.4 \%$ of all graduates participated in a co-curricular activity, spanning leadership programs, community engagement/outreach, competitions, volunteering and student clubs/societies. Interestingly, only $17.3 \%$ had participated in paid work relevant to their career during their studies.

[Insert Table 2]

Mann-Whitney tests $(\alpha=.05)$ showed a variation in participation by gender for only for-credit internships at an employer's place of work with relatively more females taking part, $\mathrm{U}=15983(\mathrm{Z}=-2.721), p=.007$. Regarding status at enrolment, significantly more school leavers participated in not-for-credit internships/placements/practicums at their own university, $\mathrm{U}=18859(\mathrm{Z}=-2.516), p=.012$. There were also reported differences for those that were firstin-family to attend university. Significantly more graduates whose family members before them had attended university had participated in for-credit internships/placements/practicums, $\mathrm{U}=17310(\mathrm{Z}=-3.380), p=.001$, and notfor-credit internships, $\mathrm{U}=18638.50(\mathrm{Z}=-2.392), p=.017$, both at the employer's place of work. Further, relatively more graduates who were first-in-family to attend university participated in co-curricular activities, $U=19010(Z=-$ $2.243), p=.025$.

There were some recorded differences by residency with more international students participating in not-for-credit internships/placements/practicums at their own university, $\mathrm{U}=10832.5(\mathrm{Z}=-1.987), p=.047$, and relatively more domestic students participating in co-curricular activities, $\mathrm{U}=10433(\mathrm{Z}=-2.078), p=.038$. Interestingly there were only variations by discipline for for-credit client-based projects and consultancies with relatively more Creative Industries students participating, $\mathrm{U}=24563(\mathrm{Z}=-2.925), p=.003$. Kruskal-Wallis test $(\alpha=.5)$ reported a significant age effect for not-for-credit internship/placement/practicums, $\mathrm{H}(3)=10.763, p=.013$, with younger graduates 
participating more and each more mature-aged group reporting a lower mean rank. There were no reported differences by professional status prior to completing a degree.

\section{Perceived value of learning activities}

The mean ratings for the learning activities for each of the four employability indicators, and their associated standard deviations, are presented in Table 3. The means for activities with participation of greater than 20 graduates are presented in Figure 1. Results indicated that for-credit enterprise/incubation/start-up activities were considered the most useful, on average, for all four employability indicators although only six graduates participated in this activity. Interestingly, the same activity, but in not-for-credit format, was rated one of the least useful across the average and all four indicators.

[Insert Table 3 and Figure 1]

Not-for-credit internships - both university and industry-based - were highly regarded, achieving a consistently high mean relative to other activities on all four indicators. Paid work also rated well, although was perceived as relatively less useful for broadening networks. There were consistently positive ratings for for-credit internships at the employer's place of work. Embedded internships at the graduate's own university did not rate as well, particularly for broadening networks and creating employment opportunities.

For-credit remote/virtual placements/study tours were also considered valuable, particularly for broadening networks but relatively less so for creating employment opportunities. Interestingly, the equivalent not-for-credit activity attracted relatively lower ratings apart from for creating employment opportunities. Not-for-credit mentoring was considered more useful than for-credit mentoring. Their value-add was most apparent in broadening networks although both performed reasonably for creating employment opportunities but relatively weakly for learning new skills.

The mean ratings for-credit and not-for-credit industry-based projects/consultancies appeared in the lower half of all activities and for all four indicators. Similarly, co-curricular activities were considered relatively less useful although there was a notable spike in their mean ratings for broadening networks. Overall, the relative value of not-for-credit versus for-credit activities appeared broadly equal in terms of average ratings.

\section{Predictors of the perceived value of learning activities}


Before building the regression model, the normality of the outcome variables was explored. Measures of kurtosis and skew were well within accepted ranges of 7 and 2 respectively (Curran, West and Finch 1996). The selected base variables are denoted by 0 in Table 1 . For pay, the base variable was 'no pay'. The first institution, with the smallest sample size, was the assigned base variable and the shortest length of time (less than 100 hours) was the base variable for duration. There were no bivariate correlations greater than 0.6 , alleviating risk for Type II errors (Grewal, Cote and Baumgartner 2004). Computed Variance Inflation Factor (VIF) and tolerance were well within the accepted limits of +/- 2 (George and Mallery 2010), suggesting multicollinearity was not present. There was no evidence of first order linear auto-correlation given the Durbin-Watson test statistic was 2.007 and therefore close to the critical value of two (Norusis 2008). The results of the ordinary least-squares regression are presented in Table 4. Adjusted $R^{2}$ of .315 indicated reasonable model fit and the model was significant, $\mathrm{F}(9,92)=6.156$, $p<.000$.

[Insert Table 4]

Results indicated that Creative Industries graduates rated the usefulness of internships/practicums/placements as significantly lower than Business graduates. The extent to which the activity enabled individuals to interact meaningfully with professionals had a positive influence on the learning activity's perceived value for enhancing employability. Similarly, the internship's relevance to the individual's degree positively predicted its perceived value for augmenting employability.

\section{Discussion and implications}

Embedded learning activities were perceived as broadly useful to graduates' skill development, gaining of relevant experience, provision of networking opportunities and employment prospects, although in varying ways. This might suggest that engaging in a variety of activities would be useful for students over time. The lack of dazzling results for the learning activities' perceived value for creating employment opportunities accentuates the rather tenuous relationship between employability interventions and employment outcomes, despite the common misconception that employability and employment are one and the same (Pegg et al. 2012). That employability activities are not always reported to lead to improved career outcomes is a disappointing reality for both institutions and individual graduates, given their time-consuming and resource-intensive nature. In line with extant literature (Bridgstock 2019), the reported effects of learning activities on providing meaningful opportunities to interact with 
professionals were also somewhat disappointing, signalling the need for educators to embed deeper industry engagement into such learning activities.

The high level of participation reported for embedded internships reflects the spike in less traditional disciplines (such as Education and Nursing) as a means of creating positional advantage, particularly in non-professionally accredited contexts. Participation by comparatively fewer first-in-family graduates could be attributed to commonly imposed academic entry criterion which inhibits students with lower grades from participating in WIL (Dunn et al. 2016), often of lower socio-economic status (Peach et al. 2016). Relaxing such restrictive criterion and instead focusing on the demonstration of work ethic when recruitment into WIL is important for more equitable access (Jackson 2018).

Participation in ECAs could align to strategically trying to create positional advantage (Roulin and Bangerter 2013), as well as growing interest in social responsibility among millennial students (Deloitte 2018). Findings reflect the heightened popularity of extra-curricular internships (Interns Australia 2015). The fewer first-in-family students undertaking embedded and extra-curricular internships may be attributed to relatively less access to financial support and greater paid work commitments (Purcell et al. 2012), demonstrating how ECAs can perpetuate further disadvantage (Hordósy and Clark 2018). The higher incidence of school leavers, international and younger students participating in extra-curricular internships at their own university could indicate their limited attractiveness to external employers, who have been observed to favour domestic students (Gribble 2014). As these activities appear highly valuable for enhancing employability, continued facilitation of these activities by HE providers - and employing strategies to also attract first-in-family students - may prove powerful for cohorts who need to develop their limited social capital.

Both embedded and not-for-credit internships were highly regarded for gaining experience and developing skills, aligning with previous studies (Jackson 2015). Previously reported positive effects of internships on employment outcomes (Brooks and Youngson 2016) were evident more for extra-curricular than embedded formats. Acrossthe-board superior ratings for not-for-credit internships support Irwin, Nordmann and Simms' (2019) findings yet appear counter-intuitive given the absence of academic control and monitoring of mentoring/supervision, feedback and specification of learning outcomes, all integral to quality embedded internships (Smith 2012). Supremacy over for-credit offerings could reflect specific university arrangements or may evidence dissonance about participating 
in embedded WIL as a sacrifice for the academic knowledge they could gain in discipline-focused units. The relative benefits of being based with an external employer versus at university were mixed.

Findings broadly suggest the need to review embedded internships in Creative Industries to ensure their intended benefits are being realised. This, however, may not fit within the traditional internship model given these graduates are more likely to be self-employed or working in micro-businesses; need strong social networks to move from project to project; are more likely to work in firms outside their specialisms (such as a graphic designer in a government department) and in multi-disciplinary project groups; and are likely to be very challenged in initial attempts in finding relevant work and establishing a career (see Bridgstock and Cunningham 2016; Collis 2010). In this context, WIL may simply need to be different for Creative Industries students. Traditional internship models often may not fit either the student's learning needs or the configurations and activities of Creative Industries employers, particularly in terms of supervisory arrangements which can be highly problematic for smaller businesses (Jackson et al. 2016).

Findings illuminate the need to consider how WIL can be designed to facilitate meaningful interaction with professionals, particularly in virtual contexts using mediums such as Zoom or Skype. Further, findings echo previous studies which assert how close alignment between WIL and the students' course content will enhance learning outcomes, enabling them to apply theoretical knowledge (Smith 2012), and providing insight into their career of interest (Jackson 2019). That the length of the activity made no difference to perceived value for enhancing employability aligns with Irwin et al. (2019), although Jackson and Wilton (2017) found lengthier internships created more value for career development learning. Pay is unimportant to the value of the activity, contradicting McHugh (2017) who found a positive relationship between compensation and the developmental value of internships. Indeed one might expect pay would assure a better workplace experience given industry's commitment and therefore greater intent on providing meaningful and challenging work, critical to WIL. Unpaid activities raise concerns for equity, often perceived as a barrier for certain student groups to access WIL (Moore, Ferns and Peach 2015). McHugh asserts a lack of empirical exploration in this area, highlighting the need for further analysis.

The relatively low participation in co-curricular activities may largely be due to timing with award programs gaining significant traction very recently. Although their perceived value for enhancing employability is not overly 
evident in this study, the high profile and resourcing of co-curricular award programs may produce different results in coming years and their importance for broadening networks means encouraging the participation of students with weaker social and cultural capital is particularly important. The relatively greater take-up by first-in-family students could perhaps indicate a conscious awareness of the need to create positional advantage in the labour market. The lower than expected undertaking of relevant paid work could be discipline-related where access in certain business fields - Accounting, Human Resource Management and Finance - may be limited until course completion. Findings confirm the value of paid work for enhancing employability (Muldoon 2009) in several ways, prompting educators (and parents) to encourage students to seek relevant employment during university years. As noted by Goldfinch and Hughes (2007), the true value of part-time work is more likely to be harnessed with deep reflection, again emphasising the need for educators to encourage students to consider ECAs, work and universitybased learning activities in complement through portfolios or other reflective tools.

The apparent usefulness for embedded remote/virtual placements/study tours is positive given that rise in homebased working (Global Workplace Analytics 2017). The equivalent not-for-credit activities were relatively poorly rated may confirm the value of quality mentoring, supervision, and feedback that should be integral to for-credit activities (McHugh 2017). Although only undertaken by a handful of graduates, the broad benefits of for-credit enterprise incubation/start-ups were apparent and warrant close consideration by educators responsible for enhancing student employability.

There is significant interest in for-credit projects/consultancies/industry panels as a means of achieving scale in WIL (Kay, Ferns, Russell and Smith 2018). That Business graduates are relatively less active in projects/consultancies may reflect their infant engagement with WIL that is not workplace-based, compared with Creative Industries graduates who can be better versed in such arrangements (Collis 2010). Further growth across disciplines is likely given the impetus for WIL and reliance on such emerging models to accommodate larger student numbers and overcome certain barriers to participation associated with traditional WIL. Results, however, indicate caution regarding their ability to enhance all aspects of employability and close attention is required to ensure their design attracts the benefits inherent to traditional WIL. Finally, mentoring - particularly as an extracurricular arrangement - appears valuable for broadening networks and - to a lesser degree - creating employment opportunities. Educators may wish to encourage student participation by facilitating mentoring arrangements with alumni and other industry partners. 


\section{Conclusion}

Embedded learning activities were perceived as broadly useful for skill development, gaining relevant experience and networking, in varying ways. Activities did not, however, report to always lead to improved career outcomes and their perceived relative lack of impact on networking opportunities prompts further review given the strong links between social capital and employment. Internships and extra-curricular activities were considered important for enhancing employability yet differing participation among student groups emphasises the value of universities embedding or at least facilitating activities in ways that cater for all students. Findings also affirm the apparent value of paid, relevant work for improving career outcomes, highlighting the important role of universities as brokers of job opportunities. This paper makes an important contribution to pedagogy and curricular design for enhancing employability among HE students. It provides valuable insight into the perceived relative value of ECAs, paid work, co-curricular programs and WIL for enhancing employability among diverse student groups. Thus, it contributes to a sorely needed empirical evidence base for the plethora of employability strategies that exist and are often deployed based on 'what should work'. As students, institutions and governments are all investing far more in employability as a key desired outcome, studies that demonstrate the impact of different kinds of learning activities on employability from varying perspectives and with diverse cohorts are essential.

With respect to limitations, the study relied on self-report data from a single source which may be considered problematic (Podsakoff et al. 2003). These data were, however, considered most appropriate given the focus on perceived relative value of different learning activities and were gathered from three different institutions. It is also noted that there could be potential bias when rating the relevance of learning activities, being positive outcome activities may be more likely perceived as more relevant. Finally, the sample size inhibited a deeper exploration of the relatively value of a greater range of learning activities using multivariate techniques. The research highlights some key areas for future research, such as exploring whether self-sourcing their own activity was a determining factor in graduate perceptions of the relative value of not-for-credit versus embedded internships for the purposes of enhancing employability. Further, examining the valuable features of enterprise, start-up and incubator activities for a greater sample would enhance our understanding of their importance, particularly in a graduate labour market where many will need to create their own employment. 


\section{References}

AIG. (2018). Skilling: A national imperative. Canberra, ACT: Australian Industry Group.

Australian Government. (2019). Performance-based funding for the Commonwealth Grant Scheme. Canberra,

ACT: Australian Government.

Bakhshi, H., Downing, J., Osborne, M., \& Schneider, P. (2017). The Future of Skills: Employment in 2030.

London: Pearson.

Batistic, S., \& Tymon, A. (2017). Networking behaviour, graduate employability: a social capital perspective.

Education+ Training, 59(4), 374-388.

Becker, G. (1964). Human capital: A theoretical and empirical analysis, with special reference to education.

Chicago, ILL: University of Chicago Press.

Berger, D., \& Wild, C. (2017). Enhancing student performance and employability through the use of authentic assessment techniques in extra and co-curricular activities. The Law Teacher, 51(4), 428-439.

Blackmore, P., Bulaitis, Z., Jackman, A., \& Tan, E. (2016). Employability in higher education: A review of practice and strategies around the world. London: Pearson.

Bridgstock, R. \& Cunningham, S. (2016). Creative labour and graduate outcomes: Implications for higher education and cultural policy. International Journal of Cultural Policy, 22(1), 10-26.

Bridgstock, R. (2019). Graduate Employability 2.0: Learning for life and work in a socially networked world. In J. Higgs, W. Letts, and G. Crisp (Eds.), Education for Employability (Volume 2), (pp. 97-106). Rotterdam: Brill Sense.

Bridgstock, R., \& Tippett, N. (2019). Higher education and the future of graduate employability: A connectedness learning approach. London: Edward Elgar.

Bloomberg. (2018). Building tomorrow's talent: Collaboration can close emerging skills gap. Edison, NJ: Bloomberg Books.

Brooks, R., \& Youngson, P. (2016). Undergraduate work placements: an analysis of the effects on career progression. Studies in Higher Education, 41(9), 1563-1578.

Burke, C., Scurry, T., Blenkinsopp, J., \& Graley, K. (2017). Critical perspectives on graduate employability. In M. Tomlinson and L. Holmes (Eds.), Graduate employability in context, (pp. 87-107). London: Palgrave Macmillan. 
Clark, G., Marsden, R., Whyatt, J., Thompson, L., \& Walker, M. (2015). 'It's everything else you do...': Alumni views on extracurricular activities and employability. Active Learning in Higher Education, 16(2), 133147.

Clarke, M. (2017). Rethinking graduate employability: the role of capital, individual attributes and context. Studies in Higher Education, 43(11), 1923-1937.

Coates, H. (2015). Working on a dream: Educational returns from off-campus paid work. Journal of Education and Work, 28(1), 66-82.

Collis, C. (2010). Developing work-integrated learning curricula for the creative industries: Embedding stakeholder perspectives. Learning and teaching in higher education, 4(1), 3-19.

Cranmer, S. (2006). Enhancing graduate employability: Best intentions and mixed outcomes. Studies in Higher Education, 31(2), 169-84.

Cturtle and Decision Lab. (2019). International student employment outcomes and satisfaction report. Ho Chi Minh City: Cturtle.

Curran, P., West, S., \& Finch, J. (1996). The robustness of test statistics to nonnormality and specification error in confirmatory factor analysis. Psychological Methods, 1(1), 16-29.

Deeley, S. (2014). Summative co-assessment: A deep learning approach to enhancing employability skills and attributes. Active Learning in Higher Education, 15(1), 39-51.

Deloitte. (2018). 2018 Deloitte millennial survey. London: Deloitte.

Dunn, L., Schier, M., Hiller, F., \& Harding, L. (2016). Eligibility requirements for work-integrated learning programs: Using grade point averages for student participation. Asia-Pacific Journal of Cooperative Education, 17(3), 295-308.

Kay, J., Ferns, S., Russell, L., \& Smith, J. (2018). Expanding WIL possibilities: Enhancing student employability through innovative WIL models. Canberra, ACT: Australian Technology Network of Universities. Fugate, M., Kinicki, A., \& Ashforth, B. (2004). Employability: A psycho-social construct, its dimensions, and applications. Journal of Vocational Behavior, 65(1), 14-38.

George, D., \& Mallery, M. (2010). SPSS for Windows Step by Step: A Simple Guide and Reference $\left(10^{\text {th }}\right.$ edition). Boston, MA: Pearson.

Gibson, D. (2004). Role models in career development: New directions for theory and Research. Journal of Vocational Behavior, 65(1), 134-156. 
Global Workplace Analytics. (2017). 2017 State of telecommuting in the US employee workforce. Carlsbad:

Global Workplace Analytics.

Gracia, L. (2010). Accounting students' expectations and transition experiences of supervised work experience. Accounting Education, 19(1/2), 51-64.

Green, J., Carbone, A., \& Rayner, G. (2019). Employability pursuits beyond the formal curriculum: Extra and co-curricular activities. In J. Higgs, W. Letts, and G. Crisp (Eds.), Education for Employability (Volume 1) (pp. 165-176). Rotterdam: Brill Sense.

Bridgstock, R. (2019). Graduate Employability 2.0: Learning for life and work in a socially networked world. In J. Higgs, W. Letts, and G. Crisp (Eds.), Education for Employability (Volume 2), (pp. 97-106). Rotterdam: Brill Sense.

Gribble, C. (2014). Employment, work placements and Work Integrated Learning of international students in Australia. Melbourne, VIC: International Education Association of Australia.

Guilbert, L., Bernaud, J., Gouvernet, B., \& Rossier, J. (2016). Employability: Review and research prospects. International Journal for Educational and Vocational Guidance, 16(1), 69-89.

Harrell, F. (2001). Regression modelling strategies. New York, NJ: Springer-Verlag.

Hart Research Associates. (2018). Fulfilling the American dream: Liberal education and the future of work. Washington, DC: Hart Research Associates.

Holmes, L. (2013). Competing perspectives on graduate employability: Possession, position or process? Studies in Higher Education, 38(4), 538-554.

Hordósy, R., \& Clark, T. (2018). Beyond the compulsory: a critical exploration of the experiences of extracurricular activity and employability in a northern red brick university. Research in Post-Compulsory Education, 23(3), 414-435.

Hordósy, R., Clark, T., \& Vickers, D. (2018). Lower income students and the 'double deficit' of part-time work: undergraduate experiences of finance, studying and employability. Journal of Education and Work, 31(4), 353365.

Horverak J., Sandal, G., Bye, H., \& Pallesen, S. (2013). Managers' selection preferences: The role of prejudice and multicultural personality traits in the assessment of native and immigrant job candidates. European Review of Applied Psychology, 63(5), 267-275.

Irwin, A., Nordmann, E., \& Simms, K. (2019). Stakeholder perception of student employability: Does the duration, type and location of work experience matter? Higher Education, 78(5), 761-781. 
Interns Australia. (2015). Interns Australia 2015 annual survey. Ultimo, NSW: Interns Australia.

Jackson, D. (2015). Employability skill development in work-integrated learning: Barriers and best practice.

Studies in Higher Education, 40(2), 350-367.

Jackson, D. (2016). Re-conceptualising graduate employability: The construction of pre-professional identity in the higher education landscape of practice. Higher Education Research and Development, 35(5), 925-939.

Jackson, D. (2018). Applying academic selection criterion to work-integrated learning programmes: risk management or perpetuating inequality? Teaching in Higher Education, 25(1), 98-115.

Jackson, D. (2019). Preparedness for the world-of work: Gauging the workplace relevance of Australian undergraduate programs and the influence of work-integrated learning. Journal of College Student Development, 60(2), 219-239.

Jackson, D., Rowbottom, D., Ferns, S., \& Mclaren, D. (2016). Employer understanding of Work-Integrated Learning and the challenges of engaging in WIL opportunities. Studies in Continuing Education, 39(1), 35-51. Jackson, D. \& Bridgstock, R. (2018). Evidencing student success and graduate employability in the contemporary world-of-work: renewing our thinking. Higher Education Research and Development, 37(5), 984998.

Jackson, D, \& Collings, D. (2018). The influence of Work-Integrated Learning and paid work during studies on employment and underemployment outcomes among graduates. Higher Education, 76(3), 403-425.

Jackson, D., \& Wilton, N. (2017). Perceived employability among undergraduates and the importance of career self-management, work experience and individual characteristics. Higher Education Research and Development, 36(4), 747-762.

Kinash, S., Crane, L., Judd, M., \& Knight, C. (2016). Discrepant stakeholder perspectives on graduate employability strategies. Higher Education Research \& Development, 35(5), 951-967.

McHugh, P. (2017). The impact of compensation, supervision and work design on internship efficacy: Implications for educators, employers and prospective interns. Journal of Education and Work, 30(4), 367-382. McCarthy, P., \& Swayn, M. (2019). Higher education and employment in Australia: The impact of internships. Sydney, NSW: CSIRO Data61.

Moore, K., Ferns, S., \& Peach, D. (2015). Australian Collaborative Education Network student scholarship for work-integrated learning. Asia-Pacific Journal of Cooperative Education, 16(4), 241-254.

Muldoon, R. (2009). Recognizing the enhancement of graduate attributes and employability through part-time work while at university. Active Learning in Higher Education, 10(3), 237-252. 
NACE. (2018). Job outlook 2019. Bethlehem: National Association of College Employers.

Nghia, T., \& Duyen, N. (2019). Developing and validating a scale for evaluating internship-related learning outcomes. Higher Education, 77(1), 1-18.

Oliver, B. (2013). Graduate attributes as a focus for institution-wide curriculum renewal: Innovations and challenges. Higher Education Research \& Development, 32(3), 450-463.

Peach, D., Moore, D., Campbell, M., Winchester-Seeto, T., Ferns, S., Mackaway, J., \&

Groundwater, L. (2016). Building institutional capacity to enhance access participation and progression in Work-Integrated Learning. Canberra, ACT: Office of Learning and Teaching.

Pegg, A., Waldock, J., Hendy-Isaac, S., \& Lawton, R. (2012). Pedagogy for employability. York: Higher Education Academy.

Podsakoff, P., MacKenzie, S., Lee, J., \& Podsakoff, N. (2003). Common method biases in behavioral research. Journal of Applied Psychology, 88(5), 879-903.

Purcell, K., Elias, P., Atfield, G., Behle, H., Ellison, R., Luchinskaya, D., \& Tzanakou, C. (2012). Futuretrack 4: Transitions into employment, further study and other outcomes. Warwick: Warwick Institute for Employment Research.

Roulin, N., \& Bangerter, A. (2013). Students' use of extra-curricular activities for positional advantage in competitive job markets. Journal of Education and Work, 26(1), 21-47.

Silva, P., Lopes, B., Costa, M., Melo, A., Dias, G., Brito, E., \& Seabra, D. (2018). The million-dollar question: Can internships boost employment? Studies in Higher Education, 43(1), 2-21.

Smith, C. (2012). Evaluating the quality of work-integrated learning curricula: A comprehensive framework. Higher Education Research and Development, 31(2), 247-262.

Smith, M., Bell, K., Bennett, D., \& A. McAlpine. (2018). Employability in a global context: Evolving policy and practice in employability, Work-Integrated Learning, and career development learning. Wollongong, NSW: Graduate Careers Australia.

Thompson, L. Clark, J., Walker, G., \& Whyatt, J. (2013). 'It's just like an extra string to your bow': Exploring higher education students' perceptions and experiences of extracurricular activity and employability. Active Learning in Higher Education, 14(2), 135-147.

Tymon, A. (2013). The student perspective on employability. Studies in Higher Education, 38(6), 841-856.

Universities Australia (2019) Work-Integrated Learning in universities. Canberra, ACT: Universities Australia. 
Universities Australia, BCA, ACCI, AIG, \& ACEN. (2015). National strategy on Work-Integrated Learning in university education. Canberra, ACT: Universities Australia.

Williams, S., Dodd, L., Steele, C., \& Randall, R. (2016). A systematic review of current understandings of employability. Journal of Education and Work, 29(8), 877-901.

Wilton, N. (2012). The impact of work placements on skill development and career outcomes for business and management graduates. Studies in Higher Education, 37(5), 603-620. 
Table 1 Summary of participant characteristics

\begin{tabular}{|c|c|c|c|c|c|c|c|}
\hline \multirow[t]{2}{*}{ Variable } & \multirow[t]{2}{*}{ Sub-category } & \multicolumn{2}{|c|}{$\begin{array}{c}\text { Graduates 1-2 years } \\
\qquad(N=\mathbf{2 4 2})\end{array}$} & \multicolumn{2}{|c|}{$\begin{array}{c}\text { Graduates } 4-5 \text { years } \\
\qquad(N=268)\end{array}$} & \multicolumn{2}{|c|}{$\begin{array}{l}\text { Overall } \\
(N=\mathbf{5 1 0})\end{array}$} \\
\hline & & $N$ & $\%$ & $N$ & $\%$ & $N$ & $\%$ \\
\hline \multirow[t]{3}{*}{ Gender } & Male & 61 & 30.0 & 67 & 30.2 & 128 & 30.1 \\
\hline & Female & 140 & 69.0 & 149 & 67.1 & 289 & 68.0 \\
\hline & Other & 2 & 1.0 & 6 & 2.7 & 8 & 1.9 \\
\hline \multirow[t]{4}{*}{ Age } & $18-24$ & 104 & 51.7 & 106 & 48.2 & 210 & 49.9 \\
\hline & $25-34$ & 78 & 38.8 & 91 & 41.4 & 169 & 40.1 \\
\hline & $35-44$ & 15 & 7.5 & 15 & 6.8 & 30 & 7.2 \\
\hline & 45-plus & 4 & 2.0 & 8 & 3.6 & 12 & 2.8 \\
\hline \multirow[t]{2}{*}{ Residency } & International & 33 & 16.4 & 31 & 13.8 & 64 & 15.1 \\
\hline & Domestic & 168 & 83.6 & 193 & 86.2 & 361 & 84.9 \\
\hline \multirow{2}{*}{$\begin{array}{l}\text { Status at } \\
\text { enrolment }\end{array}$} & School leaver & 137 & 66.8 & 158 & 69.9 & 295 & 68.4 \\
\hline & Mature-age & 68 & 33.2 & 68 & 30.1 & 136 & 31.6 \\
\hline \multirow{3}{*}{$\begin{array}{l}\text { Professional } \\
\text { career prior to } \\
\text { degree }\end{array}$} & None & 39 & 58.2 & 36 & 52.9 & 75 & 55.6 \\
\hline & Similar to degree & 12 & 17.9 & 15 & 22.1 & 27 & 20.0 \\
\hline & Unrelated to degree & 16 & 23.9 & 17 & 25.0 & 33 & 24.4 \\
\hline \multirow[t]{2}{*}{ Parental status } & $\begin{array}{c}\text { First-in-family to attend } \\
\text { university }\end{array}$ & 69 & 34.5 & 80 & 35.4 & 149 & 35.0 \\
\hline & Not first-in-family & 131 & 65.5 & 146 & 64.6 & 277 & 65.0 \\
\hline \multirow[t]{3}{*}{ Discipline } & Business & 125 & 52.5 & 154 & 57.5 & 279 & 54.7 \\
\hline & Creative Industries & 97 & 39.2 & 97 & 36.2 & 194 & 38.0 \\
\hline & Both & 20 & 8.3 & 17 & 6.3 & 37 & 7.3 \\
\hline
\end{tabular}


Table 2 Participation in university learning activities and paid work

\begin{tabular}{|c|c|c|c|c|c|c|c|c|c|c|c|c|}
\hline \multirow[t]{2}{*}{ Activity } & \multicolumn{2}{|c|}{ Participated } & \multicolumn{3}{|c|}{ Paid (\%) } & \multicolumn{2}{|c|}{$\begin{array}{l}\text { Relevance to } \\
\text { degree }\end{array}$} & \multicolumn{2}{|c|}{$\begin{array}{l}\text { Interaction with } \\
\text { professionals }\end{array}$} & \multicolumn{3}{|c|}{ Duration (hours) } \\
\hline & $N$ & $\%$ & Yes & No & Partly & $M$ & $S D$ & $\boldsymbol{M}$ & $S D$ & $0-99$ & 100-299 & $300+$ \\
\hline For-credit & 302 & 59.2 & & & & & & & & & & \\
\hline Internship/placement - employer place-of-work & 147 & 48.7 & 9.1 & 81.1 & 9.8 & 4.06 & 0.85 & 3.63 & 1.05 & 28.4 & 53.9 & 17.6 \\
\hline Internship/placement - own university & 53 & 17.5 & 12.5 & 79.2 & 8.3 & 4.13 & 0.86 & 3.41 & 1.11 & 34.5 & 51.7 & 13.8 \\
\hline Project/consultancy with industry/community partner & 69 & 22.8 & 5.0 & 95.0 & 0.0 & 3.95 & 1.07 & 3.17 & 1.13 & 64.5 & 35.5 & 0.0 \\
\hline $\begin{array}{l}\text { Remote/virtual placement/study tour (including work-related } \\
\text { experience) }\end{array}$ & 16 & 5.3 & 6.3 & 81.3 & 12.5 & 4.00 & 0.97 & 3.44 & 0.96 & 58.3 & 33.3 & 8.3 \\
\hline Mentoring programs (including peer/industry initiatives) & 39 & 12.9 & 9.1 & 84.8 & 6.1 & 3.91 & 1.16 & 3.28 & 1.28 & 61.9 & 33.3 & 4.8 \\
\hline Enterprise incubation/start-ups & 6 & 2.0 & 75.0 & 25.0 & 0.0 & 3.75 & 0.96 & 3.50 & 1.29 & 66.7 & 0.0 & 33.3 \\
\hline Not-for-credit & 244 & 47.8 & & & & & & & & & & \\
\hline Internship/placement - employer place-of-work & 90 & 36.9 & 24.4 & 60.5 & 15.1 & 4.05 & 0.95 & 3.86 & 0.97 & 23.9 & 46.3 & 29.9 \\
\hline Internship/placement - own university & 26 & 10.7 & 16.0 & 68.0 & 16.0 & 3.84 & 0.90 & 3.64 & 1.04 & 47.1 & 23.5 & 29.4 \\
\hline Project/consultancy & 34 & 13.9 & 6.1 & 84.8 & 9.1 & 3.75 & 1.16 & 2.97 & 1.18 & 68.4 & 15.8 & 15.8 \\
\hline Remote/virtual placement/study tour & 7 & 2.9 & 33.3 & 50.0 & 16.7 & 3.33 & 1.51 & 3.00 & 1.67 & 50.0 & 0 & 50.0 \\
\hline Mentoring programs & 34 & 13.9 & 6.5 & 87.1 & 6.5 & 3.58 & 1.34 & 3.35 & 1.28 & 72.7 & 18.2 & 9.1 \\
\hline Enterprise incubation/start-ups & 13 & 5.3 & 0.0 & 83.3 & 16.7 & 3.50 & 1.31 & 3.67 & 1.50 & 60.0 & 10.0 & 30.0 \\
\hline \multicolumn{13}{|l|}{ Co-curricular (not-for-credit) } \\
\hline $\begin{array}{l}\text { Leadership programs, community engagement/outreach, } \\
\text { competitions, volunteering, student clubs/societies. }\end{array}$ & 64 & 14.4 & 5.0 & 86.7 & 8.3 & 3.20 & 1.25 & 2.93 & 1.19 & 50.0 & 19.4 & 30.6 \\
\hline Paid work relevant to career & 76 & 17.3 & & & & 3.71 & 1.15 & 3.44 & 1.29 & 24.5 & 30.6 & 44.9 \\
\hline
\end{tabular}


Table 3 Perceived value of university learning activities and paid work

\begin{tabular}{|c|c|c|c|c|c|c|c|c|c|c|}
\hline \multirow[t]{2}{*}{ Activity } & \multicolumn{2}{|c|}{$\begin{array}{l}\text { Learning new } \\
\text { skills }\end{array}$} & \multicolumn{2}{|c|}{$\begin{array}{c}\text { Gaining relevant } \\
\text { experience }\end{array}$} & \multicolumn{2}{|c|}{$\begin{array}{c}\text { Broadening } \\
\text { networks }\end{array}$} & \multicolumn{2}{|c|}{$\begin{array}{c}\text { Creating } \\
\text { employment }\end{array}$} & \multicolumn{2}{|c|}{$\begin{array}{c}\text { Composite } \\
\text { average }\end{array}$} \\
\hline & $\boldsymbol{M}$ & $S D$ & $M$ & $S D$ & $M$ & $S D$ & $M$ & $S D$ & $M$ & $S D$ \\
\hline \multicolumn{11}{|l|}{ For-credit } \\
\hline Internship (employer) & 4.09 & 1.08 & 4.08 & 1.04 & 3.83 & 1.22 & 3.64 & 1.40 & 3.91 & 0.99 \\
\hline Internship (university) & 3.89 & 1.03 & 3.74 & 1.06 & 3.67 & 1.25 & 3.49 & 1.36 & 3.70 & 1.00 \\
\hline Project/consultancy & 3.88 & .99 & 3.60 & 1.08 & 3.48 & 1.32 & 2.97 & 1.30 & 3.48 & 0.94 \\
\hline Remote/virtual placement & 4.00 & .89 & 3.81 & 1.17 & 4.00 & 1.37 & 3.06 & .1 .39 & 3.72 & 0.97 \\
\hline Mentoring & 3.76 & 1.30 & 3.46 & 1.30 & 3.82 & 1.26 & 3.64 & 1.34 & 3.67 & 1.16 \\
\hline Incubator/start-ups & 4.25 & .96 & 4.25 & .96 & 4.00 & 1.15 & 4.50 & 1.00 & 4.25 & 0.96 \\
\hline \multicolumn{11}{|l|}{ Not-for-credit } \\
\hline Internship (employer) & 4.41 & 1.02 & 4.26 & .92 & 3.98 & 1.12 & 3.88 & 1.28 & 4.06 & 0.92 \\
\hline Internship (university) & 4.20 & .82 & 4.32 & .85 & 4.08 & .91 & 3.96 & 1.14 & 4.14 & 0.79 \\
\hline Project/consultancy & 3.75 & .95 & 3.69 & 1.18 & 3.78 & 1.01 & 3.34 & 1.33 & 3.64 & 0.85 \\
\hline Remote/virtual placement & 3.50 & 1.76 & 3.67 & 1.75 & 3.83 & 1.83 & 3.83 & 1.83 & 3.71 & 1.76 \\
\hline Mentoring & 3.68 & 1.47 & 3.77 & 1.36 & 3.90 & 1.08 & 3.52 & 1.48 & 3.72 & 1.16 \\
\hline Incubator/start-ups & 3.75 & 1.22 & 3.42 & 1.16 & 3.75 & 1.22 & 3.50 & 1.45 & 3.60 & 1.17 \\
\hline \multicolumn{11}{|c|}{ Co-curricular (not-for-credit) } \\
\hline Other & 3.73 & 1.19 & 3.49 & 1.37 & 3.90 & 1.16 & 3.39 & 1.38 & 3.63 & 1.14 \\
\hline Paid work & 4.11 & .99 & 4.21 & 1.05 & 3.76 & 1.29 & 3.74 & 1.25 & 3.96 & 0.99 \\
\hline
\end{tabular}


Table 4 Regression analysis - perceived value of for-credit-internship for employability

\begin{tabular}{lcccc} 
Variable & $\boldsymbol{B}$ & SE & $\boldsymbol{\beta}$ & $\boldsymbol{p}$-value \\
\hline Constant & 1.087 & 0.505 & & .034 \\
Paid & 0.094 & 0.363 & 0.022 & .796 \\
Part-paid & 0.339 & 0.294 & 0.102 & .253 \\
Interaction with professionals & 0.323 & 0.087 & 0.328 & $.000^{* *}$ \\
Relevance to degree & 0.366 & 0.101 & 0.313 & $.000^{* *}$ \\
Length (100-299 hours) & 0.183 & 0.2 & 0.093 & .363 \\
Length (300+ hours) & 0.464 & 0.264 & 0.179 & .082 \\
Institution Two & 0.249 & 0.223 & 0.12 & .268 \\
Institution Three & -0.395 & 0.282 & -0.146 & .164 \\
Creative Industries & -0.43 & 0.177 & -0.211 & $.017^{*}$ \\
& & & & \\
$R^{2}$ & & & & \\
Adjusted $R^{2}$ & .376 & & &
\end{tabular}

$* p<.05, * * p<.01$ 


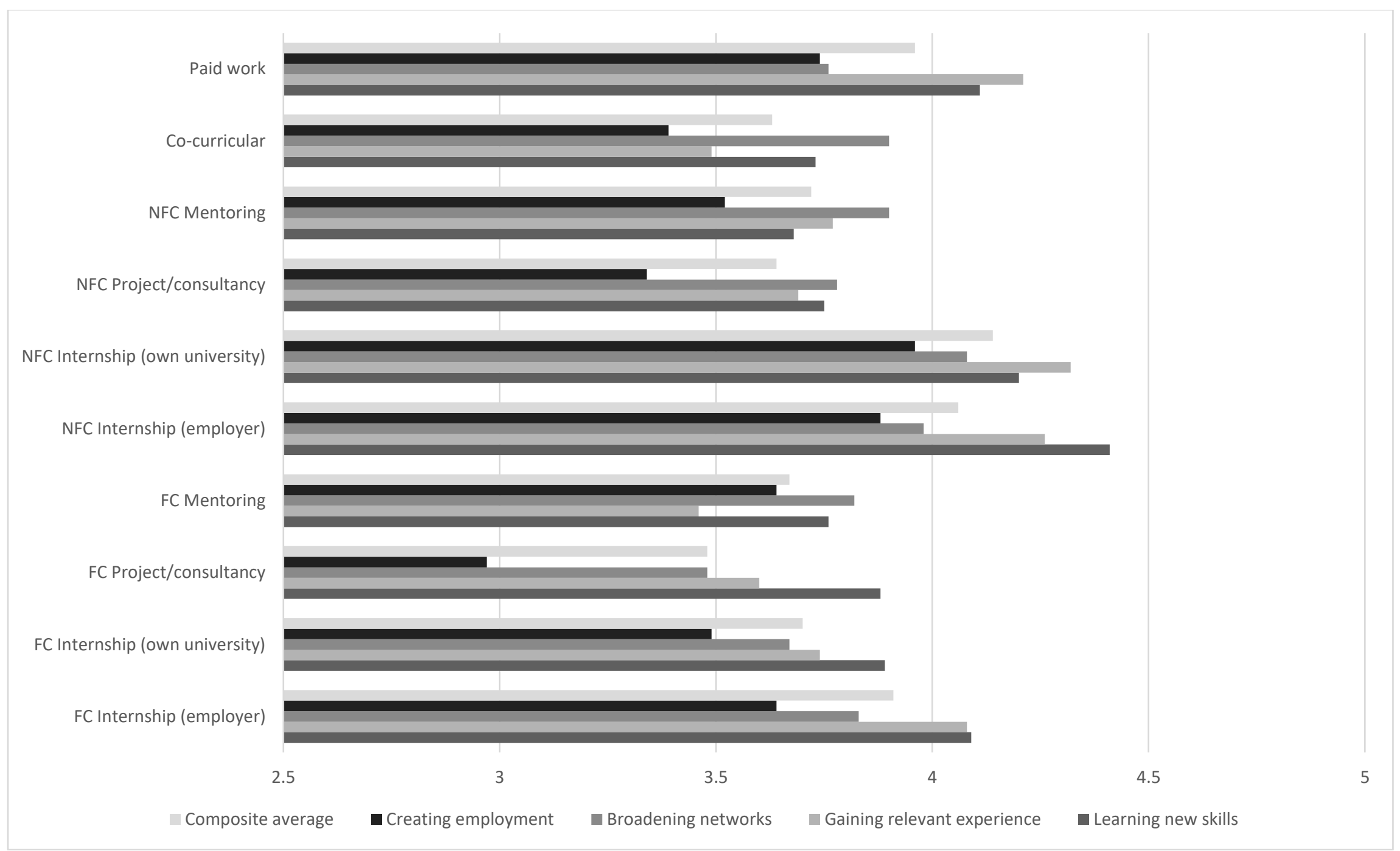

Figure 1: Value of university learning activities and paid work 